\title{
EL GRITO DE UN AVE DE RAPIÑA: CLARICE LISPECTOR FRENTE A LA FUNDACIÓN DE LA MODERNIDAD
}

\section{ARIAN A LIBERTAD SUÁREZ*}

\section{RESUMEN}

Tomando como punto de partida la tendencia de la escritura latinoamericana de finales del siglo XX a contaminar el discurso teórico y el de la ficción, se propone una relectura de la obra Un soplo de vida, de Clarice Lispector, con la finalidad de asir las referencias, apropiaciones y perlaboraciones que lleva a cabo la autora, a partir de los textos fundadores de la modernidad occidental, especialmente de la teoría hegeliana y la formación subjetiva que se desprende de la misma. Se trata pues de un acercamiento a los pliegues de estas "pulsaciones", para intentar determinar no sólo la conciencia de escritura manifiesta en toda la producción de esta autora, sino además, su finalidad dialógica y replicatoria al momento de escribir ficción.

Palabras claves: Clarice Lispector, perlaboración, teoría hegeliana, ficción/teoría.

\section{ABSTRACT}

Taking as a departure point the tendency in Latin American writing at the end of the XXth century to contaminate theoretical and fictional speech, we propose a rereading of the work Un soplo de vida (2001), de Clarice Lispector, with the purpose of grasping the references, appropriations and perlaborations that the author carries out from founding texts of western modernity, especially, of Hegelian theory and the subjective formation that parts from the same. We approach the folds to these "pulsations", to try to determine the conscience of the manifested writing in the whole production of this authoress, as well her dialogic purpose and reply in the moment she is writing fiction.

Keywords: Clarice Lispector, perlaboration, Hegelian theory, fiction/theory.

Recibido: 13.05.2005. Aprobado: 04.06.2005.

*Universidad Simón Bolívar. CIPOST- Universidad Central de Venezuela. E-mail: mariana libertad@cantv.net 
Esto no es una lamentación, es el grito de un ave de rapiña. Irisada einquieta.

Un beso en la cara muerta. Escribo como si fuese a salvar la vida de alguien. Probablemente mi propia vida. Vivir es una especie de locura quela muerte comete. Porque en ellos vivimos, vivan los muertos. De repente las cosas no tienen por quétener sentido. Me satisfago en ser.

CLARICE LISPECTOR, Un soplo de vida
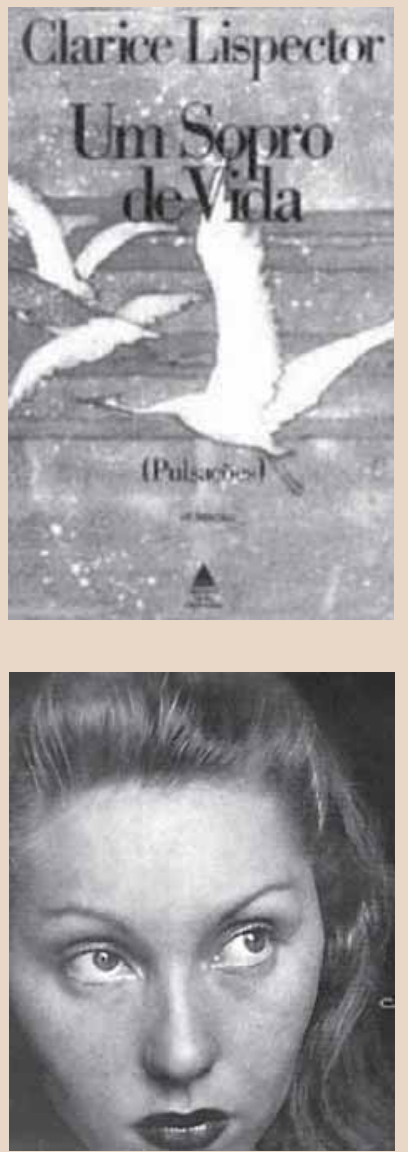

C. Lispector

\section{DEL SENTIDO AUSENTE O A MANERA DE INTRODUCCION}

Uno de los tópicos debatidos hasta el agotamiento a propósito dela literatura latinoamericana escrita por mujer en los últimos veinte años, fue la existencia o inexistencia de una escritura femenina única, tipificada e irrenunciable, cuya incuestionabilidad se desprendiera de una supuesta relación de dependencia entre el sexo/género de la autora y su esencialidad femenina aespacial, atemporal y transhistórica. Aunque, hoy por hoy, subsisten innumerables posturas que reafirman la existencia de este universal femenino y el consecuente modo único de escribir de las mujeres, la proliferación de cuestionamientos teóricos soportados en los más diversos argumentos ${ }^{1}$ tornaría arriesgado el más mínimo intento de establecer constantes dentro de la escritura de mujeres en el fin del siglo XX continental.

Todo ello se agrava si se tiene en cuenta la heterogeneidad que atraviesa y define la producción cultural de este fin de siglo en las condiciones particulares deAmérica Latina, dondea la caída delos metarrelatos legitimantes, se suma su situación de marginalidad del continente con relación al primer mundo. Entonces, resultaría aún más desatinado tratar de proponer modelos de escrituras de mujer en un espacio/tiempo donde, entre otras cosas, se ha llevado a cabo el conferimiento absoluto de la gestión cultural al mercado y -en detrimento decualquier intento de determinismo- ésteha desembocado en la multiplicación desordenada y constante de formas diversas de leer, consumir y comprender el entorno (Sarlo, 1994).

A pesar de ello, como consecuencia de ciertas afinidades genéricas, socioeconómicas y culturales que - más por contaminación que por esencialismo- definen a algunas escritoras latinoamericanas de la segunda mitad del siglo XX, no resulta demasiado difícil hallar al gunas convergencias esté

${ }^{1}$ Un claro ejemplo de las diversas perspectivas que se han empleado para refutar que exista la feminidad como esencia es la compilación: La construcción de la identidad femenina (Hernando, 2000), donde aparece una serie de artículos como el de la antropóloga Almudena Hernando, la psicoanalista Nora Levinton o la psicóloga Luisa Posada, que desde la teoría de los círculos cognitivos, el psicoanálisis lacaniano y las propuestas socioculturales de Amelia Val cárcel, respectivamente, presentan la identidad de género como una construcción simbólica absolutamente ajena a la constitución biológica del individuo. También resulta muy ilustradora la compilación: Feminismos, cuerpos y escrituras, editada por I ris Zavala (2000). 
ticas e ideológicas en sus obras. Por ejemplo, se podría proponer como una coincidencia temática, la inscripción de reflexiones teóricas de corte estético, literario e, inclusive, político dentro de los límites de las ficciones de un grupo determinado de autoras.

Todas ellas, por supuesto, definidas como subjetividades sólidas - plenamente legitimadas dentro dela máquina cultural- con proyectos de escritura quesi bien no llegan a inscribirse en el canon, siempre permanecen junto al mismo en un afán cuestionador. Como coincidencia del lugar autoral, tal vez lo más relevante sea la relación de estas escritoras con la Academia, su conocimiento probado de los problemas de la teoría contemporánea y el proceso de borramiento de límites que permite la contaminación de los espacios reflexivos y narrativos.

Esta propuesta resulta por demás llamativa, sobre todo, si se tiene en cuenta que uno de los rasgos definidores de la cultura occidental ha sido la marcada -y, eventualmente artificiosa- separación entre las producciones teóricas y las ficcionales. Dehecho, el gesto se vuelve aún más elocuentesi se recuerda que esta demarcación ha traído consigo no sólo la supuesta repartición y organización de las tipologías textuales apropiadas para cada discurso, sino que además, ha trazado un mapa ideológico para separar los asuntos de interés de uno y otro espacio del lenguaje.

Sin lugar a dudas, la recurrencia de esta delimitación dentro de la cultura occidental ha tornado aún más violento el contagio de la teoría y la ficción presente en textos como La delirios, de Carmen Boullosa (1998); Lumpérica (1983), de Diamela Eltit o Testimonio sobre M ariana (1996), de Elena Garro, escrituras donde se refrendan y/o refutan -a través, por un lado, de su estructura y, por el otro, de la topicalización del proceso de representación- los principales puntos de debate de la teoría contemporánea: el problema del lenguaje, la construcción del cuerpo, la réplica a los metarrelatos legitimantes, y las ideas de verdad y progreso histórico.

Quizás por su violencia o, probablemente, por lo temprano de su escritura, entre estos experimentos que apuestan por la desintegración de los límites entre la ficción y la teoría, uno de los más acusados -y, al mismo tiempo, atrevido- lo constituyeU n soplo devida (2001), de Clarice Lispector, novela donde las recurrencias antes mencionadas se articulan a partir de una larga reflexión en torno a la formación subjetiva y los conflictos identitarios consecuentes. Es decir, donde se ponen en escena por medio de una estructura novel esca que roza los límites de lo teatral, una buena cantidad de elementos presentes en los supuestos fundadores del pensamiento moderno occidental.

En esta obra, la construcción y deconstrucción del sujeto femenino, dela feminidad y de las identidades nacional, cultural y de género se muestran como un motivo de reflexión que-desde la polifonía y la atribución de voces totalizantes y/o contradiscursivas a los diferentes sujetos literarios que

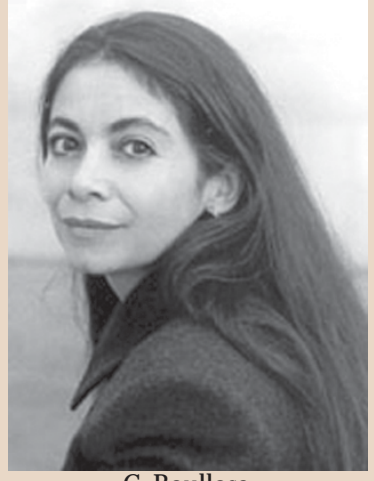

C. Boullosa

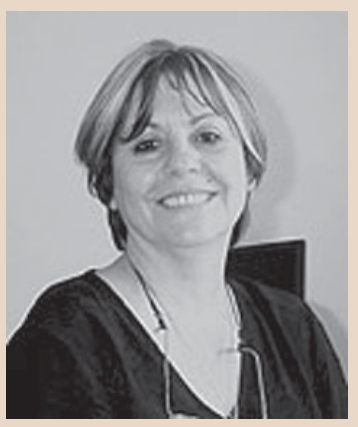

D. Eltit

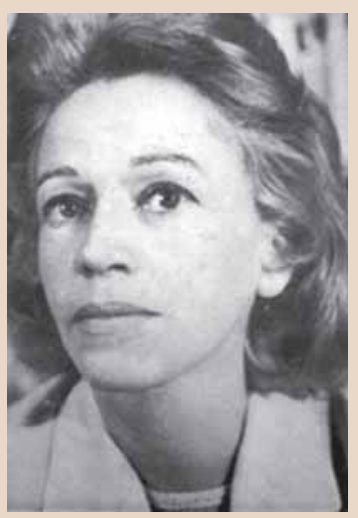

E. Garro 


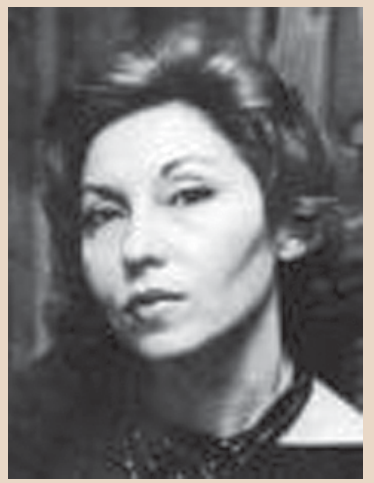

C. Lispector circulan en este relato- permite entrever un tejido filosófico dialogante, interpelador y subversivo. Quizás los elementos residuales más evidentes son aquellos que refieren la teoría hegeliana, quealuden - de manera directa o indirecta- nociones como la superación, la razón o la autoconciencia, con cierto guiño hacia la propuesta de éste y otros filósofos cuyos postulados constituyen las bases del pensamiento moderno.

Pero más allá de su reproducción, Lispector parece tomar la teoría a la fuerza y someterla a un nuevo vuelo, es decir, pareciera asumir la posición subjetiva en la que ubica al narrador de U n soplo de vida: el lugar del ave de rapiña. Por medio del encubrimiento del sujeto del discurso bajo el sujeto de la historia, Clarice Lispector se fuga en la continuidad del movimiento de la palabra postulado -años después desu escritura- por teóricoscomo Barthes (Barthes por Barthes, 1998) o Deleuze y Guattari (M il mesetas, 2000), quienes trasmutan la escritura teórica en relato ficcional y plantean, como lugar posible de arborescencia del pensamiento, el límite entre ambos espacios.

El proceso de apropiación del lenguaje como herramienta de edificación, en Un soplo de vida, es más que evidente. Lispector, en su condición de ave de rapiña, toma y subvierte la pieza que ha sido cazada por otros y descubre ese vacío que supone el advenimiento de la modernidad. Tal como lo indica la dinámica que da origen a la metáfora: frente a la muerte, las aves carroñeras quedan sin posibilidad de lamentarse, sólo se alimentan de cadáveres y -en lugar de llorarlos- deben dedicarse a destrozar el cuerpo caído hasta que desaparezca por completo. Mientras eso ocurre, las aves de rapiña sustraen la presa.

La inocencia de estas autoras, y de Lispector en especial, constituye una treta más para abrir un espacio en el campo cultural a sus enunciados subversivos. Clarice Lispector desactiva hasta marginar a las aves carroñeras -y todos sus textos fundadores de la modernidad-, para quienes suprimir del imaginario occidental cualquier resto de muerte o vacío es misión primordial.

\section{DE EXPOLIACIONES, SUJETOS, NOMADISMOS Y OTROSSUCESOS M ENORES}

\author{
Un soplo de vida \\ (Pulsaciones) \\ "Quiero escribir un movimiento puro"
}

La condición dialógica y teórica de Un soplo de vida se pone de manifiesto casi al mismo tiempo en que se inicia el contacto con el libro. El hecho de que bajo el título se pueda leer entre paréntesis la palabra "pulsaciones", seguida de la afirmación "Q uiero escribir un movimiento puro", pareciera apelar casi de inmediato a la idea de inestabilidad que atravesará la ficción. 
Ciertamente, las dos expresiones pudieran parecer difíciles de comprender sin la lectura total de la obra, pero resulta innegable que la idea de "movimiento", tanto más la de "movimiento puro", niega-desdesu definición más ortodoxa e inocente- con su sola presencia las nociones fundamentales de la narración.

En otras palabras, hablar de "movimiento puro" en esta creación de Lispector supone desarticular las nociones de recorrido y héroe épico, la presencia de un teleos que dé sentido al relato y -en consecuencia- cualquier posible trazado de una ruta, un clímax y un final. Resulta entonces imposible no pensar en qué dice con este comienzo Clarice Lispector respecto a la visión teleológica del mundo, cuál es su planteamiento en lo referente a la idea de progreso y, sobre todo, con respecto a la noción de racionalidad que atraviesa casi todo el pensamiento hegeliano?

Pero lo que resulta aún más curioso acerca de este movimiento rítmico, inconsciente e incapaz de trasladar al sujeto a ningún espacio ni fin es que se enmarca en medio de la ambigüedad que supone la estructura metaficcional del relato. En Un soplo de vida aparece un personaje denominado Autor que, a su vez, crea a un personaje llamado Angela. Esta segunda construcción - dada su condición de creación verbal con conciencia absoluta de serlo- se autoescribey objetiva al Autor hasta el extremo de obligarlo a contactar con lo real. De ahí que resulte no sólo dudoso, sino también profundamente irónico el hecho de escribir el pensamiento inicial que acompaña el título y el subtítulo de esta novela metaficcional en primera persona, pues con ello el movimiento se hace extensivo y no sólo borra los límites entre la teoría y la ficción, sino que además incorpora a la escritora, Clarice Lispector, a su propia escritura.

A esto se suma la condición de pureza atribuida al pensamiento y que, dentro de los fundamentos teóricos de la modernidad, alude de manera directa a la concepción del sujeto en el sistema hegeliano ${ }^{3}$. El Autor de Un soplo de vida quiere asir una subjetividad, por y para ello escribe. Confiesa querer "salvar la vida de alguien" a través de la escritura; sin embargo, el movimiento continuo cierra la posibilidad de unificación dela conciencia y - paradójicamente- le abre paso a la existencia de una subjetividad otra.

\footnotetext{
2 En su texto Para leer y entender a H egel, Eduardo Vásquez define la racionalidad hegeliana como la compenetración progresiva delas determinaciones del pensamiento en el mundo (Vásquez, 1993), es decir, como el resultado y el fin último de cualquier movimiento de la conciencia. Por tanto, la racionalidad resulta impensable sin las ideas de progreso, transcurrir y, sobre todo, sin una concepción teleológica del ser.

${ }^{3}$ Recordemos que según Adorno (1974) al definir al sujeto universal como pensamiento puro, Hegel abstrae de él su actividad práctico-sensible. En otras palabras, para H egel, el ser que corresponde al pensamiento no es un ser real sino una categoría filosófica: el concepto. De ahí que en la actividad del sujeto - entendido como puro intelecto- surgen las categorías, porque es lo concreto pensado. Así, el concepto, según H egel, equivale al pensamiento universal que, al pensarse a sí mismo, se objetiva, se determina, se da una existencia en y para sí (I sava, 2002).
} 
Entonces, el personaje Angela -a quien el Autor construye en un principio como un objeto utilitario que le permitirá posicionarse frente al mundo- poco a poco pasará de ser una herramienta para la satisfacción del deseo del Otro a constituirse como un objeto inal canzable que el Autor inútilmente intentará asir con sus palabras. A partir de ese momento, se desatará un juego de confusiones identitarias entre el Autor y Angela que fácilmente pudiera traducirse como un posicionamiento de Lispector frente al acto de escritura. Aún más, si se tieneen cuenta que dentro de esta ficción la autora -al igual que su personajeAutor- en un momento determinado pierdeirremediablementela voz, es decir, la capacidad en unciadora y pretendidamente organizadora del universo narrativo.

Paradójicamente, en Un soplo de vida, Angela sólo en contadas ocasiones articula un discurso coherente, en lugar de eso, grita, gruñe e incluso chilla; ella es también un ave de rapiña, pues se muestra tras un aparente silencio, para dejar claro que no tendría cabida en el universo ficcional si no hubiese un Autor/amante que hablase de ella, por ella y a través de ella o, lo que es lo mismo, que la inscribiera en al guna posibilidad subjetiva. Dentro del espacio metaficcional donde se desenvuelve, Angela se muestra como una construcción discursiva pura, cuyo deambular dentro del texto sirve como excusa perfecta para iniciar el cuestionamiento de la dimensión fundacional del acto de escritura.

A pesar de que exista sólo en el imaginario discursivo, Angela no se presenta en esta obra como un hecho poético. Nunca podría equipararse a una Dulcinea, ni siquiera a una Beatriz. Aunque su existencia sea producto del delirio de la voz que la construye, Angela está signada por la negatividad y - aunque su nombre remita a una insustancialidad ética, morfológica y tímidamente armoniosa- el giro que da el discurso desde su aparición, la relega al espacio de la mujer-monstruo que manipula, abandona su lugar previamente asignado e intenta desestabilizar la posición subjetiva del Autor. Angela se mueve con tanta rapidez queno sólo provoca contradicciones insal vables entre los pequeños discursos del Autor - lo que equivaldría a decir que contrapone el juego de voces que la nombra-, sino que además obliga al personaje masculino a perder la innegabilidad de su lugar de enunciación.

En otras palabras, en su actitud de ave de rapiña, Angela expolia la voz y la identidad que el sujeto central teje sobre ella, busca librarse del uso del lenguaje regulador y normatizante, asumeel no-decir, o decir y negar, hasta crear un espacio propio. Angela gruñe, y así intenta mantenerse al margen dela condición de sujeto que se desprendedel discurso para permanecer en el estadio primigenio del ser humano. Por eso, es al tiempo cosa-mujermadre y origen, dice de sí misma:

Yo soy materia prima no trabajada. También soy un objeto. Tengo todos los órganos necesarios, igual a cualquier ser humano. Siento mi aura que en esta 
mañana friolera es roja y llena de fulgores. Soy una mujer objeto y mi aura es roja vibrante y suficiente. Soy un objeto que ve otros objetos. Unos son mis hermanos y otros mis enemigos (...) Así sólo quedan visibles los ojos, que reflejan otros objetos. La mirada adquiere entonces un misterio tan terrible que parece la vorágine de un abismo (Lispector, 2001: 104).

Sin duda, el juego presentado por Lispector en el que el objeto asumela voz narrativa para autodesignarse y, a partir de este proceso, regodearse en su lugar marginal, puede ser entendido como una revisión más de la dialéctica hegeliana, donde no necesariamente el desenlace debe ser conciliatorio, ni losactantes -aunquetranscurra la historia- pretenden salir del lugar donde seencuentran y desde donde hablan. Cabría entonces recordar la propuesta acerca del deseo animal, frente al deseo humano, expuesta por Hegel en la Dialéctica del amo y el esclavo, y referida por Alexandre Kojeve (1987):

Si la realidad humana es una realidad social, la sociedad sólo es humana en tanto que conjunto de Deseos que desean mutuamente como Deseos. El Deseo humano, o mejor, antropógeno, que constituye un individuo libre e histórico consciente de su individualidad, de su libertad, de su historia y, finalmente, de su historicidad, el Deseo antropógeno difere pues del Deseo animal (que constituye un ser natural, sólo viviente y que no tiene más sentimiento que el de su vida) por el hecho de que se dirige no hacia un objeto real, "positivo", dado, sino sobre otro Deseo (Kojeve, 1987: 14).

A partir de esta aseveración es posible entender la representación quiásmica del deseo humano/animal, como otro de los recursos de revisión teórica empleados por Lispector. En esta obra, el sujeto-Autor, parece desear la posesión y el dominio del objeto-Angela quien, a su vez, en un movimiento altamente desestabilizador y nomádico, sólo pretende descubrir el deseo de la (Autor) idad para desarticularlo desde la exageración.

Deesta tensión sostenida - producto dela persecución del sujeto hacia el objeto y del objeto hacia el deseo del sujeto- se desprende una larga reflexión acerca dela identidad. La identidad de género, la identidad política y la identidad nacional son motivo de debate recurrente en Un soplo de vida. La primera treta discursiva empleada por Lispector es la acumulación de motivos para la escritura, mientras el Autor explica por quéy para quéescribe, los sucesos desdicen su tránsito. Mientras el Autor busca crear un perfil para su personaje, éste responde: "N o quiero ser solamenteyo misma. Quiero ser también lo queno soy" (Lispector, 2001: 49).

Angela no quiere "descubrir" (su)puesto en el mundo, sino que confiesa desear - por una parte- el esbozo de un lugar propio de enunciación y -por la otra- el desalojo de quienes se encuentran en espacios seguros y cerrados. Por eso, no es del todo sorprendente que mientras el Autor trata, sin mucho éxito, deinsertarla en una serie de construcciones sintácticas excluyentes, el 
personaje femenino acabe por presentarse como una superficie plana, sobre la que es posible acumular todas y cada una de las estructuras, hasta constituir su condición paratáctica. El carácter rizomórfico del personaje le da tintes de libertad, pues al contener en sí la premisa de base, la negación y la posibilidad no conciliatoria de convertirse en innombrable, Angela escapa de cualquier construcción subjetiva que se le pretenda atribuir.

A este respecto, es importante tener en cuenta que -al igual que ocurre dentro del discurso de muchos de los pensadores dela modernidad- la relación de Angela con el Autor se presenta, en un primer momento, como un diálogo que refuerza la dicotomía estructurante del pensamiento occidental, así como el proceso de construcción identitaria establecido dentro del mismo. Angela, en principio, se sabe diferente del Autor e idéntica a sí misma; no obstante, en la medida en queavanza el relato, semultiplica sin dejar de ser una, se desdobla y trasciende, es decir, supera su condición de personaje creado y, sin dejar de ser del todo ese personaje, pasa a ser algunos más: "Cuando me miro de fuera hacia dentro, soy una corteza de un árbol y no el árbol. Yo no sentía placer. Después de recuperar mi contacto conmigo me fecundé y el resultado fue el nacimiento alborotado de un placer en todo diferente de lo que llaman placer" (Lispector, 2001: 47).

Angela no se ve como parte de un espacio y ajena a otro, sino que parece negar, tanto en su discurso como en su proliferación, la supresión absoluta de la dicotomía sujeto-objeto que permitía - junto con la prospección del tiempo- la construcción sólida de la identidad. Angela es un espíritu que se piensa y, por tanto, que quiereser pensado en un procedimiento indisociable que niega la postura analítica clasificadora que plantea el Autor en su declaración de intenciones primera. Angela propone entonces: "Entre la palabra y el pensamiento existe mi ser. Mi pensamiento es puro aire impalpable, inasible. M i palabra es de tierra. M i corazón es vida" (Lispector, 2001: 49).

Así como el personaje, dentro de esta obra literaria la historia, las narraciones, los relatos pasan a ser pensamiento, no sistematizaciones del pensamiento, sino pensamiento puro, ese movimiento que confiesa el Autor (o el "yo" ficcionalizado de Lispector, nunca queda del todo claro) al comienzo de la novela. Al eliminar casi por completo los límites entrela prosa conceptual y el discurso ficcional, Autor y Angela se integran y cambian de significado.

Podría hablarseentonces deuna recreación del proceso dereconocimiento dela Autoconciencia, es decir, se podría hablar de la supresión de un enfrentamiento entre la conciencia ${ }^{4}$ y el objeto, o la dicotomía creador-creación, planteada en un principio dentro de Un soplo de vida. En este momento, el binarismo queda sustituido en la ficción por un "hablar de sí" que -al me-

\footnotetext{
${ }^{4}$ Eduardo Vásquez en Para leer y entender a H egel (1993) define la noción hegeliana de conciencia como: la primera etapa del conocimiento y de su metafísica, es decir, el límite entre el sujeto y el objeto.
} 
nos en un principio- parece irresoluble e inmodificable; sin embargo, se debetener en cuenta quecuando $\mathrm{H}$ egel menciona esta fase del desarrollo de la conciencia en la Fenomenología del espíritu (1994), propone que la misma desemboca en un proceso de reobjetivación de una conciencia por la otra que, irremediablemente, acaba con la muerte o sumisión de una de ellas.

Aquí surge entonces la respuesta que da la escritora a estos planteamientos ya que, a pesar de sus referencias a la muerte y la desaparición, sus afirmaciones tienden más a un proceso de desacralización, donde-en lugar de acusar la preexistencia de una fase en la que hubo una diferenciación clara entre Angela y Autor- setiende a demostrar que estas dos entidades siempre estuvieron unidas, no sólo entre ellas, sino con un todo innominado que hacia el final de la obra puedellegar a lucir sobreabarcante.

Es decir, no hace falta el curso de la historia -que, dicho sea de paso, es negado por la Autora en muchas ocasiones- para llegar a la unidad, sino que desde el momento mismo en que Lispector define las dicotomías sujeto/ objeto, dentro/fuera, arriba/ abajo como hechuras de un discurso, postulala entelequia de un plano de existencia anterior a la oralidad, donde la unidad irrenunciablemente está presente:

Angela ¿O bra? No, yo quiero la materia prima. Quiero la piedra que no ha sido esculpida.

Me he curado de la muerte. Nunca he muerto.

Veo las cosas como si ya hubiese muerto y todo estuviese lejos. Entonces viene aquella tristeza de la tela de araña en una casa abandonada (...) Pensar es tan inmaterial que ni siquiera tiene palabras (Lispector, 2001: 152).

Esta afirmación deAngela resulta por demás interpeladora, sobretodo si se tiene en cuenta que dentro de los textos fundadores de la modernidad referidos en este ejercicio de escritura, el pensamiento y la palabra, por una parte, son indisociablesy, por la otra, indican el origen dela materialidad. El sujeto es en la misma medida que se dice y reconoce por sí mismo y por el otro. De aquí que al saberse marginal y al entender esa posición como una alternativa, Angela atente contra la posibilidad de realización de la autoconciencia y, por extensión, contra cualquier posibilidad de erigir la razón como verdad.

Asimismo, estefragmento -si bien desconcierta ante la imposibilidad de universalización que atraviesa el discurso- suponeuna manera de negar las nociones definitud y deevolución sobre las que se ha pretendido construir, en occidente, las nociones de identidad de género y de identidad nacional. No hay una búsqueda por alcanzar el ideal o el deber ser, que el Autor propuso en un principio para su creación, sino que se estableceun movimiento a espacios paralel os que atenta contra la idea de progreso: "Fui trémula a mi encuentro y encontré a una mujer necia que se debate entre las paredes del 
existir. Rompo las compuertas y me creo a mí misma, nueva. En ese caso puedo encontrarme a mí misma, nueva. En ese caso puedo encontrarme conmigo, en pie de igualdad".

En otras palabras, si bien podemos reconocer un proceso de identificación del personaje consigo mismo, Angela sólo se reconoce a sí en movimiento, en un desplazamiento que no busca un telos fijo, estable, inmutable, sino que subvierte el espacio de seguridad del Autor, hasta convencerlo de que lo único quelos separa es un discurso. Pareciera, nuevamente, apelar a la Fenomenología del espíritu hegeliana y a todo el desarrollo del pensamiento posterior que se basó en la idea de finitud y completitud, desdicha constantemente en Un soplo de vida. Recordemos que para H egel:

El doblesentido delo diferenciado se halla en la esencia de la autoconciencia que consiste en ser infinita e inmediatamente lo contrario de la determinabilidad en la que es puesta. El desdoblamiento del concepto de esta unidad espiritual en su duplicación presenta antenosotros el movimiento del reconocimiento (Hegel, 1994: 113).

Es decir, desde el sistema hegeliano y en todo el tejido filosófico que se fundamentó sobre su escritura, el movimiento sólo tenía sentido -y, por tanto, se llevaba a cabo- si se perseguía al gún fin, si tras el desplazamiento subjetivo se lograba negar las diferencias y superar cierto estadio de la conciencia y alcanzar la verdad. De aquí, que al desestructurar la finalidad del movimiento, Lispector pareciera introducir en el juego de inestabilidades un nuevo elemento: la noción de futuro. De más está decir que bien como elementos futuribleso bien como certezas del porvenir, los fines motivadores dela historia están presentes en buena partedelas teorías filosóficas modernas de occidente y, de al guna manera, sirven para afirmar la idea de verdad y se legitiman en cualquier relato que concluya con la negación del vacío yla construcción de una verdad.

G. Hegel

Paradójicamente, la referencia más transgresora a este respecto no está en boca de Angela, el personaje encargado de moverse infinitamente, hasta negar la razón en sí, sino que puede leerse en las palabras del Autor:

Tengo miedo de escribir, es tan peligroso. Quien lo ha intentado, lo sabe. Peligro de revolver en lo oculto y el mundo no va a la deriva, está oculto en sus raíces sumergidas en las profundidades del mar. Para escribir tengo que instalarmeen el vacío. En estevacío donde existo intuitivamente. Pero es un vacío terriblemente peligroso: de él saco sangre. Soy un escritor que tiene miedo de la celada de las palabras: las palabras que digo esconden otras: ¿cuáles? Tal vez las digo. Escribir es una piedra lanzada en lo hondo del pozo (Lispector, 2001: 15). 
Si bien es cierto que con estas reflexiones el Autor pareciera estar refrendando la idea de la existencia implícita de la negación en cada afirmación, al hablar de un "peligro" en el instante de reconocimiento del yo en el otro, podría pensarsequehay un descrédito dela dupla pensamiento/palabra como vía de reconocimiento y posterior existencia del sujeto, es decir, al presentarse el vacío como un lugar de pronunciamiento de la autoconciencia y, al mismo tiempo, proponer que el pensamiento hecho palabra es susceptible deser desviado, se estaría negando la única posibilidad de verdad manifiesta en el sistema hegeliano ${ }^{5}$.

Aún más, podría pensarse en el movimiento puro que se proponeen este texto como un punto dearborescencia que, por medio desu multiplicación irracional y compulsiva, quiebra cualquier posibilidad dialéctica y tras el contacto - lejos de acercar el sujeto a la verdad- no sólo muestra su propia insustancialidad y la arbitrariedad de su existencia, sino que, además, hace obvia la naturaleza discursiva del yo.

Asimismo, al negar la palabra, el curso de los acontecimientos y la prospección e inclusive al negar los límites temporales que el Autor pretende mostrar al comienzo de Un soplo de vida, Lispector se pronuncia sobre la muerte. No es posibletrascender por medio del discurso, porque quien reside en la palabra no es real mente el ser humano, sino la representación simbólica que se hace del mismo, el sujeto como creación verbal. Por eso, aparecen como palabras del Autor:

Angela corre continuamente un riesgo de vida. Porque no siempre tengo fuerzas para enfrentarla a ella y a su desafío. Y enfrentándola, enfrentarme: casi sucumbo a la ley de la facilidad. Me controlo para no contar los acontecimientos de la vida de Angela. Pero caería en lo descriptivo y discursivo y eso me causaría tedio y caída ( Lispector, 2001: 148).

La vida y la muerte son estadios inexistentes, en palabras de Angela son "un chiste", por eso se atreve a per-sonar a través de máscaras subjetivas construidas por otros, y devaluar la acción fundadora del reconocimiento. Ciertamente, si -tal y como afirma Alexandre Kojeve (1987)- se entiende dentro de los postulados hegelianos como la única posibilidad de realización dela Autoconciencia el conocimiento en/por el otro, la desacralización del discurso sobre sí, por parte de Angela, podría ser entendida como una reacción antela formación subjetiva, y una inexplicable sed de existencia.

${ }^{5}$ Theodor Adorno (1974) explica al respecto que: La suposición dela experiencia como un modo deser, como algo presubjetivamente"acontecido" o "despejado" es, simplemente, incompatible con la forma en que Hegel aprehende la experiencia - como "movimiento dialéctico que la conciencia efectúa en sí misma, tanto en su saber como en su objeto, hasta el punto de que el nuevo verdadero brote ante ella a partir deél". 
Lo que el Autor postula como "riesgo de vida" es asumido por Angela como "riesgo de ser un ente discursivo", sujeto/objeto de la palabra, anquilosado, clasificabley unívoco. Angela seescabulle del único discurso facultado para reconocerla y convertirla en sujeto, acaba por afirmar: "He sido hecha para quenadiemenecesite" (Lispector, 2001: 152). Curiosamente, en el apartado final de la obra, aunque se indica que habla Angela, el Autor toma la palabra, pero no cierra (no logra cerrar) su discurso, sino que se suspende en el tiempo que en lugar de transcurrir, como propondría H egel, para la evolución dela historia, parece haber retrocedido, haberse consumido hasta el agotamiento.

Paradójicamente, Lispector parece entonces proponer la existencia de un punto de llegada equiparable al que propone ese discurso fundador al que ella parece contestar; no obstante, lo que en Hegel luce como un proyecto utópico cuyo telos es la realización del sujeto, en la Autora es un discurso atópico que culmina en la desrealización y el retorno a la materia previa a la entrada en el U niverso simbólico. O, en otros términos, la revisión que propone Lispector de la teoría hegeliana no es tanto para refutar su concepción de la historia y de la subjetividad, sino más bien para presentar como una alternativa del ser permanecer al margen, de lo que en opinión del pensador moderno era, debía ser la búsqueda del ser humano.

\section{BIBLIOGRAFIA}

Adorno, Theodor. 1974. Tres estudios sobre H egel. Madrid: Taurus.

Astutti, Adriana. 2003. "Nacida en fuga. Sobre 'La araña' de Clarice Lispector". En: Bazar Americano. Abril-mayo.

Chatelet, Francois. 1972. Hegel según Hegel. Barcelona: Editorial Laia.

H egel, G.W.F. 1983. Estética. Buenos Aires. Ediciones Siglo Veinte.

H egel, G.W.F. 1994. Fenomenología del espíritu. M éxico: Fondo de Cultura Económica.

Hernando, Almudena. 2000. La construcción dela identidad femenina. M adrid: Instituto de Investigaciones Feministas de la Universidad Complutense de M adrid.

Isava, Luis M iguel. 2002. A puntes del seminario: Textos fundadores de la teoría contemporánea. Universidad Simón Bolívar (inédito).

Kojeve, Alexandre. 1987. La dialéctica del amo y del esclavo en Hegel. Buenos Aires: LaPléyade.

Lispector, Clarice. 2001. Un soplo de vida. Madrid: Siruela.

Piro, Guillermo. 2002. "Para leer a Clarice Lispector. La descortesía de Dios”. En: El Clarín. Suplemento de cultura. 15 junio. Buenos Aires.

Porto, Regina (coord.). 1976. Clarice Lispector. Um enigma. IndiceCultura- Editoria Especial. Rio de Janeiro.

Sarlo, Beatriz. 1994. Escenas de la vida posmoderna. Argentina: Ariel. 
Sarlo, Beatriz. 2000. La máquina cultural. La Habana, Cuba: Fondo Editorial Casa delas Américas.

Vásquez, Eduardo. 1993. Para leer y entender a H egel. M érida, Venezuela: Consejo de Publicaciones, Universidad de los Andes.

Vásquez, Eduardo. 1998. Hegel un desconocido. M érida, Venezuela: Consejo de Publicaciones, Universidad de los Andes.

Zavala, Iris (ed). 2000. Feminismos, cuerpos y escrituras. Santa Cruz deTenerife, España: La Página Ediciones, S.L. 